London, £6.50) has succeeded so manifestly in making cellular immunology comprehensible as to make one wonder what ever was the problem. The twenty short chapters are divided into four sections. The first, on lymphocyte populations, deals with the origin and distribution of lymphoid tissue, cell interactions in antibody formation, cell interactions in cell-mediated responses, properties of $\mathrm{B}$ and $\mathrm{T}$ cells, and the major histocompatibility complex. The second section is the best part of the book and deals with mechanisms of cellular cooperation in the immune response. The six chapters of this section cover effector and helper cells in antibody formation and in cell-mediated responses, mechanisms of effector cell helper cell cooperation, receptors and signals, the role of the macrophage, and development of B-cell function. In the third section, one senses a potential dilemma which the

\section{Fascination of genetics}

SEVERAL textbooks of genetics were published in 1977, each appealing to different tastes.

I. H. Herskowitz's Principles of Genetics (Collier Macmillan: London, second edition, $£ 12.75$ ), one of the standard textbooks of genetics, is about twice the size of the author's Genetics published in 1962. This is clear evidence of the considerable increase in our knowledge of the subject over the past decade. But there has also been some shift of emphasis, for now the genetics of man is given more prominence than previously. This is essentially a complete course textbook of genetics covering the entire field at the undergraduate level. Each chapter concludes with a section summarising the main points, and general and specific references; and, as in the author's other books, photographs of eminent geneticists are included for interest. There are also questions and problems, with detailed answers at the end of the book, an exceptional number of diagrams and illustrations, a glossary and an excellent index. To my mind this is one of the best undergraduate textbooks of general genetics currently available.

D. L. Hartl's Our Uncertain Heritage: Genetics and Human Diversity (Blackwell Scientific: Oxford, $£ 11.20$ ), is based on a course the author has taught to undergraduates in the humanities and therefore assumes the reader has little background knowledge of human biology. It follows the traditional topics and style of similar texts with sections on Mendelism, chromosomal abnormalities, and the basics of biochemical genetics and population genetics. Possibly as a soupson for those interested in the more social aspects of human biology, the author has inclu- author has dealt with fairly. The subject of this section is immunoglobulins, and although it is not an exhaustive coverage, sufficient information is provided for an immunobiology course. The fourth section covers immunoregulation in four chapters on proliferation and maturation of cells in the immune response, regulator $T$ cells, the genetics of the immune response, and immunological tolerance. The presentation of the material is good and the clear simple figures contribute greatly to the elucidation of complex experimental designs. This is a first rate book of which the greatest virtue is its step by step approach which will aid immunobiology students greatly.

\section{T. D. Heath}

T. D. Heath is a research fellow in the Division of Biology of the Institute of Cancer Research working at the Chester Beatty Research Institute, London, UK.

ded chapters on cancer, race, human origins and genetic engineering.

Each chapter in Hartl's book concludes with references for further reading but these are often sadly out of date (the most up-to-date reference on prenatal diagnosis is 1971). The illustrations are generally good but the time-honoured Royal pedigree of haemophilia, which the author discusses at some length, is incorrect. There is not a great deal which makes this textbook any different from many others from which it will have very strong competition. I still feel that the best textbook of human genetics currently available for non-science socially-orientated students is Lerner and Libby's Heredity, Evolution and Society (Freeman: San Francisco, second edition, 1976, £8.80).

Genetics Study Guide by M. E. Conklin and D. L. Hartl (Lippincott: Philadelphia, Pennsylvania, paperback $\$ 5.95)$, is quite a different type of book and, in many ways, unique. The authors believe that " . . . merely reading about genetics is quite a different matter from truly understanding how the laws of heredity operate"-genetics has first of all to be clearly understood. It is to this end that the authors have produced this book, which consists of 23 chapters ranging over the entire field of human genetics. Each chapter has a glossary of terms followed by questions and problem-solving exercises. There are also four crossword puzzles designed to help the student learn the vocabulary of genetics. The Guide is meant to accompany an introductory textbook of genetics (such as Hartl's own book). The intention throughout is to make the student an active participant in the learning process. Unfortunately, as no answers are provided, this is not a self-instructional text and would require the answers to be submitted to a teacher-presumably the reason for the pages being perforated so that they can be easily torn out. If the intention is for the student to teach himself, then a selfinstructional or programmed text (such as A. Vegotsky and C. A. White's A Programmed Approach to Human Genetics, Wiley: New York, 1974), might be considered preferable to a Study Guide which would seem superfluous to a good teacher sensitive to the problems and needs of his students.

It is becoming increasingly clear that many important hereditary characters both in man and other organisms are not inherited in a simple Mendelian manner but show continuous variation with no sharp distinction between different classes. Biometrical genetics is the study of such continuous variation and $\mathrm{K}$. Mather and J. L. Jinks' Introduction to Biometrical Genetics (Chapman and Hall: London, hardback $£ 8.50$; paperback $£ 4.50$ ), is a worthy successor to their more comprehensive Biometrical Genetics which was intended for the specialist. Their new book is directed more toward senior undergraduates. In general, no more than simple algebra is needed, though on a few occasions, such as in discussing additive and dominance effects, the authors resort to matrix inversion. Rather idiosyncratically, $T$ is used for heritability and not the usual $h^{2}$ which is used for something else. Examples are chosen almost exclusively from plants and animals and despite the authors' admission that ". . . man offers many advantages for the study of populations", biometrical methods in human genetics are dealt with in a mere dozen pages. It would certainly be useful to have an introductory text on the biometrical genetics of man particularly because of the importance of continuous variation in many medically important traits.

Finally, there is E. Novitski's Human Genetics (Collier Macmillan: London, $£ 10.50$ ), intended to interest the more junior undergraduate in the subject but at the same time provide him with some understanding of the many problems facing humanity from developments in this field. Thus, detailed discussions of population and biochemical genetics are sacrificed in order to place greater emphasis on the effects of radiation, transplantation and such socially important issues as the genetics of intelligence and race, genetic counselling and prenatal diagnosis. Each chapter concludes with a list of references, though very few are later than 1973, and a list of questions. It is clearly and attractively laid out and well illustrated with line drawings and many interesting photographs.

Each book will appeal to readers with different backgrounds and interests, which presumably is in part a reflection of the fascination of genetics.

Alan E. H. Emery

Alan E. H. Emery is Professor of Human Genetics at the University of Edinburgh, Scotland. 